\title{
Safety, Tolerability, and Efficacy of Insulin Aspart in People with Type 2 Diabetes, as Biphasic Insulin Aspart or with Basal Insulin: Findings from the Multinational, Non-Interventional $\mathrm{A}_{1}$ chieve Study
}

Issam Hajjaji $\cdot$ Siddharth Shah $\cdot$ Yuxiu Li $\cdot$ Vinay Prusty $\cdot$ Youcef Benabbas $•$ Philip D. Home

To view enhanced content go to www.diabetestherapy-open.com

Received: December 18, 2013 / Published online: January 30, 2014

(c) The Author(s) 2014. This article is published with open access at Springerlink.com

\section{ABSTRACT}

Introduction: The aim of the study was to investigate the clinical safety and effectiveness of starting insulin aspart (aspart) therapy in people with type 2 diabetes mellitus (T2DM) as a sub-analysis of the multinational, noninterventional A1chieve study.

Methods: Insulin-naïve and insulinexperienced people with T2DM in routine clinical care starting aspart alone at baseline and continuing aspart alone, changing to

Trial registration: NCT00869908.

Electronic supplementary material The online version of this article (doi:10.1007/s13300-014-0052-4) contains supplementary material, which is available to authorized users.

I. Hajjaji ( $\square)$

National Centre for Diabetes and Endocrinology, PO Box 7948, Ain Zara, Tripoli, Libya

e-mail: imhajjaji@gmail.com

S. Shah

Bhatia Hospital, Saifee Hospital, S.L Raheja-Fortis Hospital, Mumbai, India

Y. Li

Department of Endocrinology, Key Laboratory of Endocrinology, Ministry of Health, Peking Union Medical College Hospital, Peking Union Medical College, Chinese Academy of Medical Sciences,

Beijing, China biphasic insulin aspart 30 (aspart premix) or adding a basal insulin by study end, were included. Safety, tolerability, and efficacy were evaluated over 24 weeks.

Results: Overall, 3,898 people started aspart at baseline. Of the 3,313 with 24-week data, 1,545 (46.6\%) continued with aspart, 1,379 (41.6\%) switched to aspart premix, and 214 (6.5\%) added basal insulin, while the remainder switched to other regimens. No serious adverse drug reactions were reported. The proportion of participants reporting hypoglycemia decreased from baseline to week 24 in the aspart alone group $(11.2 \%$ versus $4.1 \%, p<0.001)$ and in the aspart + basal insulin group $(13.1 \%$ versus $7.5 \%, p=0.040$ ), and was $3.7 \%$ at week 24 in the aspart premix group. The mean HbA1c

V. Prusty

Novo Nordisk A/S, Zurich, Switzerland

Y. Benabbas

Diabetology Unit, Department of Internal Medicine, University Hospital of Constantine, Ain Smara, Constantine, Algeria

P. D. Home

Newcastle University, Newcastle upon Tyne, UK 
decreased from baseline to week 24 (aspart: $-2.1 \pm 2.0 \% \quad[-23 \pm 22 \mathrm{mmol} / \mathrm{mol}], \quad$ aspart premix: $\quad-2.3 \pm 1.7 \% \quad[-25 \pm 19 \mathrm{mmol} / \mathrm{mol}]$, aspart + basal insulin: $\quad-2.0 \pm 2.1 \%$ $[-22 \pm 23 \mathrm{mmol} / \mathrm{mol}] ; p<0.001)$.

Conclusion: Insulin aspart therapy was well tolerated and was associated with improved glucose control over 24 weeks in people with T2DM.

Keywords: A1chieve; Aspart; Basal insulin; Biphasic insulin aspart; Type 2 diabetes

\section{INTRODUCTION}

The progressive nature of type 2 diabetes mellitus (T2DM) necessitates that medications are continually optimized to achieve and maintain recommended or individualized metabolic goals $[1,2]$. In time, insulin therapy is almost inevitably required as islet $\mathrm{B}$ cell function declines, and with time, insulin regimens have to be further optimized to maintain control to target. However, in some people, overly rigorous intensification of blood glucose control can impair a person's health by leading to increased risk of hypoglycemia [3]. This gives rise to challenges in identifying and implementing suitable insulin regimens for individuals in clinical practice.

Information to assist such decision making can come not only from randomized clinical trials (RCTs), but also from non-interventional studies that allow for selection of a larger, more representative heterogeneous patient population, also allowing collection of larger datasets of efficacy, safety, and tolerability outcomes.

Insulin aspart (aspart) is a rapid-acting mealtime insulin analogue studied in a number of RCTs $[4,5]$. In several RCTs, meal-time insulin alone was started in people with T2DM, on occasion with optimization of therapy by later addition of a basal insulin [6-8]. It has been suggested that this is appropriate as the progression of insulin deficiency in T2DM follows from an initial insufficiency of postprandial glucose control [9].

Postprandial hyperglycemia has been putatively linked to increased risks of macrovascular disease, diabetic retinopathy, and decreased myocardial blood volume and myocardial blood flow [10-13], and studies show aspart lowers postprandial plasma glucose (PPPG) levels to a greater extent than unmodified human insulin [14]. Insulin aspart is also available as a premix preparation (biphasic insulin aspart) and can be combined with a basal insulin in a mealtime + basal insulin regimen. In the $4 \mathrm{~T}$ (Treating to Target in Type 2 diabetes) study, blood glucose control and hypoglycemia at 3 years were comparable for basal insulin added to aspart, aspart added to biphasic insulin aspart, and aspart added to a basal insulin [7].

The $A_{1}$ chieve study [15] included people with T2DM on aspart, biphasic insulin aspart 30 (aspart premix), and insulin detemir in 28 countries in routine clinical practice, albeit for a shorter period of time. The present subgroup analysis was conducted to investigate the clinical safety, tolerability, and effectiveness of aspart therapy in a cohort of insulin-naïve and insulin-experienced patients starting aspart alone at baseline and continuing with aspart alone, switching to aspart premix, or adding a basal insulin during the study.

\section{MATERIALS AND METHODS}

\section{Study Design}

$\mathrm{A}_{1}$ chieve was a multinational, 24-week, noninterventional study to assess the safety and 
effectiveness of the insulin analogs, aspart NovoRapid $^{\circledR}$, Novo Nordisk, Bagsvaerd, Denmark), aspart premix $\left(\right.$ NovoMix $^{\circledR}$, Novo Nordisk), and detemir (Levemir $^{\circledR}$, Novo Nordisk), in routine clinical care [15]. The participating countries were grouped into seven regions: China, South Asia (Bangladesh, India, Pakistan), East Asia (Indonesia, Korea, Malaysia, Philippines, Singapore, Taiwan), North Africa (Algeria, Morocco, Tunisia, Libya), Middle East + Gulf (Egypt, Iran, Jordan, Turkey, Bahrain, Kuwait, Oman, Qatar, Saudi Arabia, United Arab Emirates, Yemen), Latin America (Argentina, Mexico), and Russia. This sub-analysis was conducted in a cohort of previously insulin-naïve or insulin-experienced patients starting aspart therapy at baseline and then continuing on aspart alone, switching to aspart premix, or adding a basal insulin, at the discretion of their physicians, during the 24-week study period.

There were no pre-defined study procedures and the participating physicians were responsible for all aspects of the patient care, including the decision to appropriately modify therapies. Study insulins were commercially available and used as per routine clinical practice. Data for analysis were collected for pre-study, baseline (insulin day 1), interim visit (around 12 weeks from baseline), and final visit (around 24 weeks from baseline). The use of oral glucose-lowering drugs (OGLDs) was permitted throughout the study at the physicians' discretion.

\section{Patients}

Any participant who started therapy on aspart alone in the 4 weeks prior to baseline and continued using aspart alone, switched to aspart premix, or added a basal insulin by study end was eligible for this sub-analysis.
Women who were pregnant, breast-feeding, or had the intention of becoming pregnant were not included.

\section{Compliance with ethics}

This article does not contain any new studies with human or animal subjects performed by any of the authors. All participants provided signed informed consent and ethics committee approvals were obtained for each participating country.

\section{Assessments and Outcomes}

The primary outcome measure was the incidence of serious adverse drug reactions (SADRs), including major hypoglycemic events. Secondary outcomes included the number of serious adverse events (SAEs), and the change in the proportion of participants that reported hypoglycemic events during the 4 weeks preceding baseline and week 24. A hypoglycemic event was defined as an event with symptoms of hypoglycemia that resolved with oral carbohydrate intake, glucagon or intravenous glucose, or any symptomatic or asymptomatic event with a plasma glucose level of $\quad 3.1 \mathrm{mmol} / \mathrm{l} \quad(56 \mathrm{mg} / \mathrm{dl})$. Nocturnal hypoglycemic events were defined as individualized symptomatic events consistent with hypoglycemia, occurring during sleep, after the evening insulin injection and before getting up in the morning, and if relevant, before morning determination of fasting plasma glucose (FPG) and the morning insulin injection. Major hypoglycemic events were defined as events with severe central nervous system symptoms consistent with hypoglycemia in which the patient was unable to self-treat and characterized by either a plasma glucose level of $3.1 \mathrm{mmol} / \mathrm{l}(56 \mathrm{mg} / \mathrm{dl})$, or reversal of symptoms 
after either food intake, glucagon or intravenous glucose administration.

Other secondary outcomes included the change from baseline to week 24 in $\mathrm{HbA}_{1 \mathrm{c}}$, FPG, PPPG, systolic blood pressure, body weight, and lipid profile. Health-related quality of life (HRQoL) was assessed based on the change in visual analog scores (VAS) of the EQ-5D questionnaire [16] from baseline to week 24 .

Laboratory measurements were performed by local laboratories following local standardization and quality control procedures.

\section{Statistical Analysis}

Statistical analyses were performed for the groups that continued aspart alone, switched to aspart premix or added a basal insulin during the study. Continuous and discrete variables were summarized using descriptive statistics (mean, SD) and frequency tables $(n, \%)$, respectively. Two-sided tests at a pre-specified $5 \%$ significance level were used for all statistical analyses. The change from baseline to study end in the proportion of patients reporting at least one hypoglycemic event was analyzed using McNemar's test. The change from baseline to study end for all other outcomes was analyzed using Student's paired $t$ test. All data were analyzed by Novo Nordisk personnel using SAS $^{\circledR}$ (Version 9.1.3, SAS, Cary, NC, USA).

\section{RESULTS}

\section{Baseline Characteristics and Glucose- Lowering Regimens}

A total of 3,898 people with T2DM started therapy with aspart alone \pm OGLDs at baseline, of whom 3,313 patients had data available by study end. The remaining 585 patients were withdrawn due to loss of contact (434 patients), adverse drug reaction (1 patient), and other reasons (150 patients). By region, 1,244 participants from China, 1,851 from South Asia, 494 from East Asia, 70 from North Africa, 197 from Middle East + Gulf, 19 from Latin America and 23 from Russia started aspart alone \pm OGLDs at baseline.

The physicians' main reason for starting aspart therapy was to improve glycemic control $(92.2 \%$ for participants continuing aspart alone, $96.7 \%$ for switchers to aspart premix and $93.0 \%$ for those adding a basal insulin).

Of the 3,313 completers, 1,545 patients (46.6\%) continued with aspart alone, 1,379 (41.6\%) switched to aspart premix, and 214 (6.5\%) added basal insulin by week 24 . Other participants switched to detemir (39, 1.2\%), added aspart premix to aspart $(86,2.6 \%)$ or moved to diverse other regimens (50, 1.5\%), and are not discussed further as the number of patients was too low for statistical significance. Baseline characteristics for the three groups analyzed are presented in Table 1.

The majority of participants were on at least one OGLD at baseline with metformin and sulfonylureas being the most commonly used OGLDs in all groups (Table 1). At week 24, the proportions of patients on 1 OGLD, 2 OGLDs, and more than 2 OGLDs were 55.5, 41.3, and $3.2 \%$, respectively, in the aspart group; 70.6, 27.0 , and $2.5 \%$, respectively, in the aspart premix group, and $75.8,17.6$, and $6.6 \%$, respectively, in the aspart + basal insulin group.

\section{Insulin Dose and Frequency of Administration}

Insulin doses and administration frequencies for each group pre-study, at baseline and at 
Table 1 Demographic and baseline characteristics

\begin{tabular}{llll}
\hline & \multicolumn{2}{l}{ Insulin regimen at week 24 } & \\
\cline { 2 - 4 } & Aspart alone & Aspart premix & Aspart + basal \\
\hline$n$ & 1,545 & 1,379 & 214 \\
Male/female (\%) & $58.8 / 41.2$ & $58.0 / 42.0$ & $51.4 / 48.6$ \\
Age (years) & $53.0(13.3)$ & $54.6(12.0)$ & $53.4(13.0)$ \\
Body weight $(\mathrm{kg})$ & $67.7(13.0)$ & $70.0(11.9)$ & $70.0(15.7)$ \\
Body mass index $\left(\mathrm{kg} / \mathrm{m}^{2}\right)$ & $25.2(4.0)$ & $25.7(3.9)$ & $25.8(4.9)$ \\
Duration of diabetes (years) & $7.4(6.3)$ & $6.5(5.3)$ & $8.5(6.7)$ \\
Duration on insulin (years) & $1.1(2.7)$ & $0.8(2.1)$ & $1.8(3.3)$ \\
HbA $1 \mathrm{c}(\% / \mathrm{mmol} / \mathrm{mol})$ & $9.4(1.9) / 79(21)$ & $9.6(1.7) / 81(19)$ & $9.4(2.0) / 79(22)$ \\
Oral glucose-lowering drugs, $n(\%)$ & & & 91 \\
Total $n$ & 983 & 860 & $68(74.7)$ \\
Metformin & $772(78.5)$ & $640(74.4)$ & $20(22.0)$ \\
Sulfonylureas & $370(37.6)$ & $270(31.4)$ & $63(69.2)$ \\
One & $604(61.4)$ & $604(70.2)$ & $22(24.2)$ \\
Two & $340(34.6)$ & $237(27.6)$ & $6(6.6)$ \\
$>$ Two & $39(4.0)$ & $19(2.2)$ & \\
\hline
\end{tabular}

Data are mean $(\mathrm{SD})$, or as stated

week 24 are presented in Table 2. The mean daily \pm SD insulin dose by weight at week 24 was $0.43 \pm 0.21 \mathrm{U} / \mathrm{kg} /$ day in the aspart alone group, $0.42 \pm 0.19 \mathrm{U} / \mathrm{kg} /$ day in the aspart premix group, and $0.72 \pm 0.29 \mathrm{U} / \mathrm{kg} /$ day in the aspart + basal group.

In the aspart alone group at baseline, 51.9\% of participants used it thrice daily, evolving in those continuing aspart alone to $41.5 \%$ twice daily and $49.7 \%$ thrice daily by week 24 . In the group switching to aspart premix, 58.6\% started aspart thrice daily at baseline, while $85.6 \%$ were on twice daily aspart premix at week 24 . In the group adding a basal insulin, $72.3 \%$ and $80.8 \%$ were administering aspart at least thrice daily at baseline and week 24, respectively.

\section{SADRs and SAEs}

NoSADRs were reported in any of the participants during the study. Four SAEs (upper gastrointestinal hemorrhage, hepatic coma, chronic renal failure, and vascular stenosis) were reported in those continuing aspart alone, two (pyrexia and herpes zoster) in those changing to premix, and one (melaena) in those adding a basal insulin. All SAEs were considered unlikely to be related to the study drugs.

\section{Hypoglycemia}

Data for hypoglycemia in the 4 weeks prebaseline and pre-week 24 are presented in Table 3. A statistically significant decrease in the 
Table 2 Insulin dose and dosing frequency at pre-study, baseline and week 24

\begin{tabular}{|c|c|c|c|}
\hline & \multicolumn{3}{|c|}{ Insulin regimen at week 24} \\
\hline & Aspart alone & Aspart premix & Aspart + basal \\
\hline \multicolumn{4}{|c|}{ Insulin dose (U/day) } \\
\hline$n$ & 1,545 & 1,379 & 214 \\
\hline Pre-study & $33.0(18.5)$ & $34.8(16.4)$ & $39.6(23.6)$ \\
\hline Baseline & $27.5(13.5)$ & $30.3(12.0)$ & $26.3(14.1)$ \\
\hline Week 24 & $28.0(13.3)$ & $28.6(13.1)$ & $49.1(22.3)$ \\
\hline \multicolumn{4}{|c|}{ Insulin dose by body weight (U/kg/day) } \\
\hline$n$ & 1,468 & 1,347 & 199 \\
\hline Pre-study & $0.49(0.28)$ & $0.50(0.24)$ & $0.57(0.32)$ \\
\hline Baseline & $0.42(0.22)$ & $0.44(0.18)$ & $0.40(0.22)$ \\
\hline Week 24 & $0.43(0.21)$ & $0.42(0.19)$ & $0.72(0.29)$ \\
\hline \multicolumn{4}{|c|}{ Daily dose frequency } \\
\hline Pre-study, $n$ (\%) & 423 & 332 & 125 \\
\hline Once & $89(21.0)$ & $63(19.0)$ & $39(31.2)$ \\
\hline Twice & $201(47.5)$ & $205(61.7)$ & $44(35.2)$ \\
\hline Thrice & $102(24.1)$ & $40(12.0)$ & $22(17.6)$ \\
\hline$>$ Thrice & $31(7.3)$ & $24(7.2)$ & $20(16.0)$ \\
\hline Baseline, $n(\%)$ & 1,545 & 1,378 & 213 \\
\hline Once & $98(6.3)$ & $59(4.3)$ & $24(11.3)$ \\
\hline Twice & $592(38.3)$ & $380(27.6)$ & $19(8.9)$ \\
\hline Thrice & $802(51.9)$ & $807(58.6)$ & $154(72.3)$ \\
\hline$>$ Thrice & $53(3.4)$ & $132(9.6)$ & $16(7.5)$ \\
\hline Week 24, n (\%) & 1,544 & 1,379 & 214 \\
\hline Once & $94(6.1)$ & $63(4.6)$ & 0 \\
\hline Twice & $641(41.5)$ & $1,181(85.6)$ & $17(7.9)$ \\
\hline Thrice & 767 (49.7) & $132(9.6)$ & $24(11.2)$ \\
\hline$>$ Thrice & $42(2.7)$ & $3(0.2)$ & $173(80.8)$ \\
\hline
\end{tabular}

Data are mean $(\mathrm{SD})$, or as stated

proportion of patients reporting confirmed anytime hypoglycemia between baseline and week 24 was noted in the aspart alone group $(11.2 \%$ versus $4.1 \%, p<0.001)$, and the aspart + basal insulin group $(13.1 \%$ versus $7.5 \%, p=0.040)$, while there was no statistically significant change in the aspart premix group (5.1\% versus $3.7 \%$, NS). No events of major hypoglycemia were reported in the 4 weeks preceding week 24 in any of the groups. 
Table 3 Hypoglycemia in the 4 weeks before baseline and before week 24

Insulin regimen at week 24

\begin{tabular}{|c|c|c|c|c|c|}
\hline \multicolumn{2}{|l|}{ Aspart alone } & \multicolumn{2}{|c|}{ Aspart premix } & \multicolumn{2}{|c|}{ Aspart + basal } \\
\hline $\begin{array}{l}\text { Rate (event/ } \\
\text { person-year) }\end{array}$ & $\begin{array}{l}\text { Percent with at } \\
\text { least } 1 \text { event }(\%)\end{array}$ & $\begin{array}{l}\text { Rate (event/ } \\
\text { person-year) }\end{array}$ & $\begin{array}{l}\text { Percent with at } \\
\text { least } 1 \text { event }(\%)\end{array}$ & $\begin{array}{l}\text { Rate (event/ } \\
\text { person-year) }\end{array}$ & $\begin{array}{l}\text { Percent with at } \\
\text { least } 1 \text { event }(\%)\end{array}$ \\
\hline
\end{tabular}

Overall

$\begin{array}{llcllll}\text { Baseline } & 3.82 & 11.2 & 1.56 & 5.1 & 4.62 & 13.1 \\ \text { Week 24 } & 1.06 & 4.1 & 1.09 & 3.7 & 1.76 & 7.5 \\ p & & <0.001 & & 0.066 & & 0.040 \\ \text { Major } & & & & & \\ \text { Baseline } & 0.43 & 1.9 & 0.16 & 1.1 & 0.36 & 1.4 \\ \text { Week 24 } & 0.0 & 0.0 & 0.0 & 0.0 & 0.0 & 0.0 \\ p & & <0.001 & & 0.001 & & 0.083 \\ \text { Minor } & & 10.6 & 1.40 & 4.6 & 4.25 & 12.6 \\ \text { Baseline } & 3.39 & 4.1 & 1.09 & 3.7 & 1.76 & 7.5 \\ \text { Week 24 } & 1.06 & <0.001 & & 0.235 & & 0.063 \\ p & & & & & & \\ \text { Nocturnal } & & 5.4 & 0.42 & 2.0 & 1.15 & 6.1 \\ \text { Baseline } & 1.12 & 0.6 & 0.26 & 1.4 & 0.12 & 0.9 \\ \text { Week 24 } & 0.10 & <0.001 & & 0.160 & & 0.005 \\ p & & & & & & \end{array}$

Overall is confirmed or major anytime hypoglycemia

$p$-value was calculated using McNemar's test for the proportion of patients experiencing hypoglycemia

From baseline to week 24, the proportion of patients reporting nocturnal hypoglycemia significantly decreased in the aspart alone group $(5.4 \%$ versus $0.6 \%, p<0.001)$, and in the aspart + basal insulin group $(6.1 \%$ versus $0.9 \%, p=0.005)$, but not in the aspart premix group (2.0\% versus $1.4 \%$, NS).

\section{Blood Glucose Control}

The mean $\mathrm{HbA}_{1 \mathrm{c}}$ level decreased similarly from baseline to week 24 in all three groups: from $9.4 \pm 1.9 \%(79 \pm 21 \mathrm{mmol} / \mathrm{mol})$ to $7.3 \pm 1.1 \%$ $(56 \pm 12 \mathrm{mmol} / \mathrm{mol})$ in the aspart alone group; from $\quad 9.6 \pm 1.7 \% \quad(81 \pm 19 \mathrm{mmol} / \mathrm{mol}) \quad$ to $7.3 \pm 0.9 \%(56 \pm 10 \mathrm{mmol} / \mathrm{mol})$ in the aspart premix group; and from $9.4 \pm 2.0 \%$ $(79 \pm 22 \mathrm{mmol} / \mathrm{mol}) \quad$ to $\quad 7.4 \pm 1.3 \%$ $(57 \pm 14 \mathrm{mmol} / \mathrm{mol}) \quad$ in the aspart + basal insulin group (all $p<0.001$, Table 4 ). At week $24,36.5,32.1$, and $45.0 \%$ of participants in groups ending on aspart alone, aspart premix, and aspart + basal insulin had $\mathrm{HbA}_{1 \mathrm{c}}$ levels $<7.0 \%(<53 \mathrm{mmol} / \mathrm{mol})$ compared to $8.6,4.8$, and $6.7 \%$ at baseline. The mean FPG and postbreakfast PPPG levels also decreased to a clinically and statistically significant extent in all three groups (all $p<0.001$, Table 4). 
Table 4 Blood glucose control at baseline and after 24 weeks

\begin{tabular}{|c|c|c|c|}
\hline & \multicolumn{3}{|c|}{ Insulin regimen at week 24} \\
\hline & Aspart alone & Aspart premix & Aspart + basal \\
\hline \multicolumn{4}{|c|}{$\mathrm{HbA}_{1 \mathrm{c}}(\% / \mathrm{mmol} / \mathrm{mol})$} \\
\hline$n$ & 1,067 & 1,119 & 144 \\
\hline Baseline & $9.4(1.9) / 79(21)$ & $9.6(1.7) / 81(19)$ & $9.4(2.0) / 79(22)$ \\
\hline Week 24 & $7.3(1.1) / 56(12)$ & $7.3(0.9) / 56(10)$ & $7.4(1.3) / 57(14)$ \\
\hline Change & $-2.1(2.0) /-23(22)$ & $-2.3(1.7) /-25(19)$ & $-2.0(2.1) /-22(23)$ \\
\hline$p$ & $<0.001$ & $<0.001$ & $<0.001$ \\
\hline \multicolumn{4}{|c|}{ FPG $(\mathrm{mmol} / \mathrm{L})$} \\
\hline$n$ & 1,308 & 1,197 & 156 \\
\hline Baseline & $10.6(3.5)$ & $11.6(4.2)$ & $10.5(4.4)$ \\
\hline Week 24 & $7.3(2.0)$ & $7.7(2.4)$ & $7.3(2.8)$ \\
\hline Change & $-3.3(3.2)$ & $-3.9(3.4)$ & $-3.2(4.7)$ \\
\hline$p$ & $<0.001$ & $<0.001$ & $<0.001$ \\
\hline \multicolumn{4}{|c|}{ PPPG (mmol/L) } \\
\hline$n$ & 991 & 935 & 116 \\
\hline Baseline & $15.2(4.7)$ & $16.5(5.3)$ & $14.5(4.8)$ \\
\hline Week 24 & $10.0(3.1)$ & $11.0(3.7)$ & $9.6(3.3)$ \\
\hline Change & $-5.2(4.5)$ & $-5.5(4.2)$ & $-4.9(4.9)$ \\
\hline$p$ & $<0.001$ & $<0.001$ & $<0.001$ \\
\hline
\end{tabular}

Data are mean (SD), or as stated

$F P G$ fasting plasma glucose, $H b A_{1 c}$ glycated hemoglobin $\mathrm{A}_{1 \mathrm{c}}, P P P G$ postprandial plasma glucose

\section{Lipids, Body Weight, and Systolic Blood}

\section{Pressure}

All measures of the lipid profile (Table 5) improved to a similar extent in the three groups, but low ascertainment and thus small numbers meant that this was not confirmed statistically in the aspart + basal insulin group except for total serum cholesterol.

There was no clinically or statistically significant change in body weight in the aspart alone and aspart premix groups, but a gain of $0.9 \pm 3.5 \mathrm{~kg}$ by week 24 in the group adding basal insulin was statistically significant $(p<0.001)$ (Table 5).

Clinically and statistically significant decreases in systolic blood pressure levels were noted in all three groups by 24 weeks (Table 5).

\section{Quality of Life}

The mean HRQoL improved from baseline to week 24 in all three groups as measured by the EQ-5D VAS score (aspart alone, $64.8 \pm 16.7$ to $79.2 \pm 10.8$ points; aspart premix, $61.5 \pm 17.6$ to $77.1 \pm 10.8$ points; and aspart + basal 
Table 5 Baseline and 24-week data for blood lipids, body weight and systolic blood pressure

Insulin regimen at week 24

\begin{tabular}{lll}
\hline Aspart alone & Aspart premix & Aspart + basal
\end{tabular}

Total cholesterol $(\mathrm{mmol} / \mathrm{l})$

$n$

Baseline

Week 24

Change

$p$

Triglycerides $(\mathrm{mmol} / \mathrm{l})$

$n$

Baseline

Week 24

Change

$p$

HDL cholesterol $(\mathrm{mmol} / \mathrm{l})$

n

Baseline

Week 24

Change

$p$

LDL cholesterol $(\mathrm{mmol} / \mathrm{l})$

n

Baseline

Week 24

Change

p

Body weight $(\mathrm{kg})$

$n$

Baseline

Week 24

Change

$p$
297

$5.1(1.2)$

$4.6(0.9)$

$-0.4(1.1)$

$<0.001$

322

$1.9(1.1)$

$1.7(0.7)$

$-0.3(0.9)$

$<0.001$

287

$1.2(0.4)$

$1.2(0.4)$

$0.1(0.4)$

$<0.001$

292

$3.0(1.0)$

$2.7(0.8)$

$-0.2(0.9)$

$<0.001$

1,367

$67.4(12.8)$

67.6 (12.1)

$0.1(2.7)$

0.102
324

$5.2(1.4)$

$4.7(1.2)$

$-0.6(1.3)$

$<0.001$

327

$2.0(1.1)$

$1.8(0.8)$

$-0.2(0.9)$

$<0.001$

298

$1.1(0.3)$

$1.2(0.4)$

$0.1(0.3)$

0.005

306

$3.2(1.0)$

$2.9(1.1)$

-0.4 (1.2)

$<0.001$

1,217

70.0 (11.7)

70.1 (11.2)

$0.1(2.6)$

0.312
62

$5.0(1.7)$

$4.6(1.0)$

$-0.4(1.4)$

0.03

54

$2.0(1.3)$

$1.9(0.9)$

$-0.2(1.0)$

0.21

50

$1.1(0.3)$

$1.2(0.3)$

$0.1(0.2)$

0.057

51

$2.9(0.9)$

$2.6(0.9)$

$-0.2(1.0)$

0.083

182

70.1 (16.2)

71.0 (15.3)

$0.9(3.5)$

$<0.001$ 
Table 5 continued

\begin{tabular}{llll}
\hline & \multicolumn{2}{c}{ Insulin regimen at week 24 } & Aspart + basal \\
\cline { 2 - 4 } & Aspart alone & Aspart premix & \\
\hline Systolic blood pressure (mmHg) & & 166 \\
$n$ & 1,064 & 1,055 & $133.0(18.2)$ \\
Baseline & $132.3(17.1)$ & $138.7(22.2)$ & $126.7(14.2)$ \\
Week 24 & $127.9(14.4)$ & $127.1(12.0)$ & $-6.3(14.9)$ \\
Change & $-4.3(15.3)$ & $-11.6(21.5)$ & $<0.001$ \\
\hline$p$ & $<0.001$ & $<0.001$ &
\end{tabular}

Data are mean (SD), or as stated

$H D L$ high-density lipoprotein, $L D L$ low-density lipoprotein

insulin, $68.4 \pm 18.0$ to $77.7 \pm 12.2$ points; all $p<0.001)$.

\section{DISCUSSION}

This sub-analysis confirms the clinical safety and effectiveness of aspart therapy, whether administered as prandial insulin alone, as the premixed analogue biphasic insulin aspart (and thus including protaminated aspart) or when combined with a basal insulin in a mealtime + basal regimen. While it is uncommon in global clinical practice to begin any insulin regimen with meal-time insulin alone, of the 66,726 people enrolled in $A_{1}$ chieve on four continents, this was the case in 3,898 (5.8\%), with some variation from country to country.

Having begun meal-time aspart, adding a basal insulin or switching to a biphasic insulin regimen was common (48\%) within 24 weeks and are accepted methods of therapy intensification that allow coverage of both meal-time and basal insulin requirements [17, 18]. However, by study end a substantial proportion (47\%) were still taking aspart alone, suggesting that these patients were then in satisfactory glucose control or were reluctant to further intensify their regimen. Clearly, the majority of study participants were initially seen as having a predominantly meal-time insulin requirement, given the small proportion of participants who subsequently added a basal insulin (7\%) to the initial aspart regimen.

Baseline characteristics (age, body weight, and BMI) were broadly similar across the three groups, but $\mathrm{A}_{1}$ chieve was not a randomized study, and it cannot be assumed that the populations were comparable in other ways. Use of a multiple injection regimen (aspart + basal) offers more opportunity for dose titration, and the higher insulin dose in this group reflects the high dose in the group on aspart + basal insulin in the overall $\mathrm{A}_{1}$ chieve cohort [15]. Such people are often judged as more insulin deficient, consistent with this group having modestly longer duration of diabetes from diagnosis (8.5 years) compared with those who continued aspart alone (7.4 years) or changed to aspart premix (6.5 years). The statistically significant improvements in $\mathrm{HbA}_{1 \mathrm{c}}$ were consistent with those reported for the main study and were 
comparable between the three groups at 24 weeks. The FPG and PPPG levels also improved to clinically large extents in all three groups (all $p<0.001$ ). This is consistent with the observational INSTIGATE study, where useful reductions in FPG levels were also reported from meal-time aspart therapy alone [19]. Indeed, the improvements in FPG levels with aspart in routine clinical practice are better than found in RCTs [20] and, together with the improvements in systolic blood pressure, lipid profile and the lack of weight gain, led us to suggest that starting the insulin analogues in $A_{1}$ chieve may have also been an opportunity to improve lifestyle measures [15]. Such changes in lifestyle would be expected to minimize differences between the insulin regimens.

Insulin aspart therapy was well tolerated with no SADRs reported in any group during the study, consistent with the large body of clinical experience gained in the past 10 years. Interestingly, there was a decrease from baseline to week 24 in the proportion of participants reporting both confirmed anytime and nocturnal hypoglycemia in the aspart alone group and the aspart + basal group. The findings are consistent with those from the main study, from a sub-analysis of use of the aspart + basal insulin regimen in older people $[15,21]$. For the aspart premix group, data interpretation is complicated by a lower baseline rate of anytime hypoglycemia, although the 24-week rate is not notably different from the other two groups; however, the change was not statistically significant. While reporting fatigue may have been an issue, or the state of the population in the 4 weeks to baseline, it is again possible that the opportunity of starting insulin aspart was used to enhance lifestyle management, including avoidance of hypoglycemia.
It is encouraging that HRQoL was found to rise in all three groups from baseline to 24 weeks. All three groups used multiple injections, so it seems clear that this did not subtract significantly from the gains that would be associated with the marked improvement of blood glucose control. Gains in HRQoL have been noted in RCTs even where multiple injections were used [22]. Again, however, it is also possible that the circumstance in which the participants in $A_{1}$ chieve started insulin may have resulted in other enhancements of clinical care and that these and the lifestyle changes combined to enhance life quality. The statistically significant improvements seen in the lipid profile in the aspart alone and aspart premix groups, and in total cholesterol in the aspart + basal insulin group may also have contributed to the improved HRQoL at week 24 .

Limitations of the $A_{1}$ chieve study included the lack of randomization, which may mean that different results in different populations merely reflect different clinical habits or population phenotypes. However, the results here are strikingly similar among the three defined study groups, and the changes within each group sufficiently notable to be of interest without comparison between groups. As this was a non-interventional study, nonstandardization of study procedures across sites and regions may also be a factor. Other useful information would have been dietary and exercise changes, circumstances of starting the insulin analog (e.g., in-patient care, referral to a specialist), and non-diabetes-related medications. These, as discussed above, limit data interpretation. Collection of hypoglycemia data based on the patient's recall of hypoglycemic events may have been problematic, particularly in regard of baseline, though if anything the results are seemingly high for that observational point. However, this 
large, non-interventional study did provide an opportunity to investigate treatment outcomes related to the use of different regimens of aspart therapy in around 3,000 people in routine care in countries with either a lower resource base or recent economic evolution.

\section{CONCLUSION}

In conclusion, insulin aspart therapy was observed to be well tolerated and efficacious in routine clinical practice in people with T2DM, whether administered as meal-time injections only, as the biphasic formulation, or in combination with a basal insulin.

\section{ACKNOWLEDGMENTS}

The authors would like to thank all participants who provided data and all investigators involved in the $A_{1}$ chieve study. The authors would like to thank Chunduo Shen of Novo Nordisk for providing statistical analysis. The authors would also like to thank Anjali Philip of Cognizant Technology Solutions for writing assistance, funded by Novo Nordisk. This study was sponsored by, and article processing charges were paid by, Novo Nordisk A/S, Denmark. The sponsor took part in the development of the protocol, the process of data collection and analysis, funding of medical writing services, and in reviewing the manuscript, but not in participant selection, choice of therapies (study or otherwise), provision of therapies including insulin or continuing clinical management of the participants.

All authors had full access to all of the data in this study and take complete responsibility for the integrity of the data and accuracy of the data analysis.
All named authors meet the ICMJE criteria for authorship for this manuscript and have given final approval for the version to be published. Vinay Prusty is the guarantor for this article and takes responsibility for the integrity of the work as a whole.

Funding. This study was sponsored by Novo Nordisk A/S, Denmark.

Conflict of interest. IH served as a consultant (Advisory Board) for MSD and received honoraria for lectures from MSD. SS has no conflicts of interest to declare. YL received a research grant from Eli Lilly. VP is employed by Novo Nordisk A/S. YB is an advisory board member of Novo Nordisk; has served as a speaker sponsored by Novo Nordisk, Pfizer, Eli Lilly, Sanofi, Novartis and Astra Zeneca and is a key opinion leader for Novo Nordisk, Pfizer, MSD and Sanofi. PH or institutions with which he is associated receive funding from Novo Nordisk and other insulin manufacturers for his research, advisory and educational activities.

Compliance with ethics. This article does not contain any new studies with human or animal subjects performed by any of the authors. All participants provided signed informed consent and ethics committee approvals were obtained for each participating country.

Open Access. This article is distributed under the terms of the Creative Commons Attribution Noncommercial License which permits any noncommercial use, distribution, and reproduction in any medium, provided the original author(s) and the source are credited. 


\section{REFERENCES}

1. Turner RC, Cull CA, Frighi V, Holman RR. Glycemic control with diet, sulfonylurea, metformin, or insulin in patients with Type 2 diabetes mellitus: progressive requirement for multiple therapies (UKPDS 49). UK Prospective Diabetes Study (UKPDS) Group. J Am Med Assoc. 1999;281(21):2005-12.

2. Inzucchi SE, Bergenstal RM, Buse JB, American Diabetes Association (ADA), European Association for the Study of Diabetes (EASD), et al. Management of hyperglycaemia in type 2 diabetes: a patient-centered approach: position statement of the American Diabetes Association (ADA) and the European Association for the Study of Diabetes (EASD). Diabetes Care. 2012;35(6):1364-79.

3. Dhar GC. Intensive glycemic control: implications of the accord, advance, and VADT trials for family physicians. Can Fam Physician. 2009;55(8):803-4.

4. Rosenfalck AM, Thorsby P, Kjems L, et al. Improved postprandial glycaemic control with insulin aspart in type 2 diabetic patients treated with insulin. Acta Diabetol. 2000;37(1):41-6.

5. Heller S, McCance DR, Moghissi E, Nazeri A, Kordonouri O. Diversity in diabetes: the role of insulin aspart. Diabetes Metab Res Rev. 2012;28(1):50-61.

6. Bretzel RG, Nuber U, Landgraf W, Owens DR, Bradley C, Linn T. Once-daily basal insulin glargine versus thrice-daily prandial insulin lispro in people with type 2 diabetes on oral hypoglycaemic agents (APOLLO): an open randomised controlled trial. Lancet. 2008;371(9618):1073-84.

7. Holman RR, Farmer AJ, Davies MJ et al., 4-T Study Group. Three-year efficacy of complex insulin regimens in type 2 diabetes. $\mathrm{N}$ Engl J Med. 2009;361(18):1736-47.

8. Riddle MC, Rosenstock J, Vlajnic A, Gao L. Randomized, 1-year comparison of three ways to initiate and advance insulin for type 2 diabetes: twice-daily premixed insulin versus basal insulin with either basal-plus one prandial insulin or basalbolus up to three prandial injections. Diabetes Obes Metab. 2013. doi:10.1111/dom.12225.

9. Monnier L, Colette C, Dunseath GJ, Owens DR. The loss of postprandial glycemic control precedes stepwise deterioration of fasting with worsening diabetes. Diabetes Care. 2007;30(2):263-9.
10. DECODE Study Group. Glucose tolerance and cardiovascular mortality: comparison of fasting and 2-hour diagnostic criteria. Arch Intern Med. 2001;161:397-405.

11. Nakagami T, Qiao Q, Tuomilehto J, et al. Screendetected diabetes, hypertension and hypercholesterolemia as predictors of cardiovascular mortality in five populations of Asian origin: the DECODA study. Eur J Cardiovasc Prev Rehabil. 2006;13(4):555-61.

12. Shiraiwa $T$, Kaneto $H$, Miyatsuka $T$, et al. Postprandial hyperglycemia is a better predictor of the progression of diabetic retinopathy than $\mathrm{HbA}_{1 \mathrm{c}}$ in Japanese type 2 diabetic patients. Diabetes Care. 2005;28(11):2806-7.

13. Scognamiglio $\mathrm{R}$, Negut $\mathrm{C}$, De Kreutzenberg SV, Tiengo A, Avogaro A. Postprandial myocardial perfusion in healthy subjects and in type 2 diabetic patients. Circulation. 2005;112(2):179-84.

14. Rys P, Pankiewicz O, Łach K, Kwaskowski A, Skrzekowska-Baran I, Malecki MT. Efficacy and safety comparison of rapid-acting insulin aspart and regular human insulin in the treatment of type 1 and type 2 diabetes mellitus: a systematic review. Diabetes Metab. 2011;37(3):190-200.

15. Home P, Naggar NE, Khamseh $M$, et al. An observational non-interventional study of patients with diabetes beginning or changed to insulin analogue therapy in non-Western countries: the A1chieve study. Diabetes Res Clin Pract. 2011;94:352-63.

16. EuroQol Group. EuroQol-a new facility for the measurement of health-related quality of life. Health Policy. 1990;16(3):199-208.

17. American Diabetes Association. Standards of medical care in diabetes-2013. Diabetes Care. 2013;36(Suppl 1):S11-66.

18. IDF Clinical Guideline Task Force. Global Guideline for Type 2 Diabetes: recommendations for standard, comprehensive, and minimal care. Diabet Med. 2006;23(6):579-93.

19. Liebl A, Jones S, Goday A, et al. Clinical outcomes after insulin initiation in patients with type 2 diabetes: 24-month results from INSTIGATE. Diabetes Ther. 2012;3(1):9.

20. Holman RR, Thorne KI, Farmer AJ, 4-T Study Group, et al. Addition of biphasic, prandial, or basal insulin to oral therapy in type 2 diabetes. N Engl J Med. 2007;357:1716-30. 
21. Latif ZA, Hussein Z, Litwak L, El Naggar N, Chen JW, Soewondo P. Safety and effectiveness of insulin aspart in Basal-bolus regimens regardless of age: a1chieve study results. Diabetes Ther. 2013;4(1):103-18.

22. Testa MA, Gill J, Su M, Turner RR, Blonde L, Simonson DC. Comparative effectiveness of basal- bolus versus premix analog insulin on glycemic variability and patient-centered outcomes during insulin intensification in type 1 and type 2 diabetes: a randomized, controlled, crossover trial. J Clin Endocrinol Metab. 2012;97(10):3504-14. 